\title{
ENSINAR LINGUÍSTICA NA ESCOLA: UM CONFRONTO COM A REALIDADE
}

\author{
TEACHING LINGUISTICS AT SCHOOL: \\ A CONFRONTATION WITH REALITY
}

\author{
Sandra Quarezemin | Lattes | sandra@cce.ufsc.br \\ Universidade Federal de Santa Catarina
}

\begin{abstract}
Resumo: Este artigo trata da linguística como matéria de ensino na escola. A ideia é contrastar, por meio de um diálogo crítico, a abordagem gramatical contemporânea com a gramática escolar. A finalidade deste trabalho é refletir sobre a inserção da linguística no contexto escolar, considerando a realidade enfrentada pelos professores de gramática e pelos alunos. Este estudo também mostra que a linguística pode mudar as relações professor-aluno e de ensino-aprendizagem dentro do espaço escolar. Não se tem a intenção de relacionar o ensino da linguística à arte de bem escrever. A proposta apresentada privilegia a entrada da linguística na escola enquanto estudo científico e descritivo de fenômenos gramaticais do português brasileiro. Este trabalho está ancorado em Perini (2006, 2010, 2016) e no estudo recente de Pires de Oliveira e Quarezemin (2016).
\end{abstract}

Palavras-chave: Linguística; Gramática; Escola; Ensino-aprendizagem.

\begin{abstract}
This article presents the linguistics as teaching subject in the school. The idea is to contrast, through a critical dialogue, the contemporary grammatical approach with the grammar taught at schools. The purpose of this work is to reflect on the insertion of linguistics in the school context, considering the reality faced by grammar teachers and students. In addition to showing that linguistics can change the relations teacher-student and the teaching-learning relationships inside the school. We do not intend to relate the teaching of linguistics to the art of writing well. The proposal presented favors the entrance of linguistics into the school as a scientific and descriptive study of grammatical phenomena of Brazilian Portuguese. This work is based on Perini $(2006,2010,2016)$ and on the recent study by Pires de Oliveira and Quarezemin (2016).
\end{abstract}

Key-words: Linguistics; Grammar; School; Teaching-learning. 


\section{Introdução}

Neste trabalho, apresentamos uma reflexão acerca do ensino de gramática nas escolas. ${ }^{1} \mathrm{Na}$ verdade, como o próprio título do texto evidencia, defendemos a entrada da linguística nas aulas de gramática do português. A inserção da linguística nas escolas não significa dar, por exemplo, uma aula de sintaxe ou de morfologia nos mesmos moldes que é feito dentro da universidade. Longe disso! Acreditamos que a linguística, bem como a física, a química ou a biologia, é uma ciência que pode ser empregada para despertar no aluno/aprendiz a curiosidade pela sua própria língua, além de fornecer subsídios ao professor de gramática sobre o funcionamento da língua portuguesa.

A finalidade é mostrar aos professores de gramática como esse conhecimento pode ser trabalhado com o aluno sem a necessidade de seguir um ensino normativo/tradicional. Mas sabemos que isso não é uma tarefa fácil, por isso, não desconsideramos a realidade do professor quando se trata de questões de ensino-aprendizagem. Cabe ressaltar que não é a nossa intenção dar uma receita de como as aulas de gramática devem ser, ao invés disso, propomos uma alternativa capaz de auxiliar o professor durante o estudo da gramática.

As aulas de língua portuguesa carecem de um trabalho sobre gramática capaz de tornar o conhecimento explícito da língua em um conjunto de saberes ao qual os alunos podem recorrer em contextos de uso diversificados, tornando-se usuários conscientes da sua língua. Neste contexto, problematizamos a participação do aluno no processo de aprendizagem. Muitas vezes, a falta de motivação está diretamente relacionada ao fato de que esse aluno não é um agente participativo no processo de ensino-aprendizagem. O trabalho do professor não deve se limitar à transmissão de conhecimento como algo acabado, principalmente quando nos referimos ao ensino de línguas.

A proposta que defendemos neste texto está fundamentada nos estudos de Pires de Oliveira e Quarezemin (2016) e de Perini (2006, 2010, 2016). A questão central é introduzir o estudo científico da linguagem nas escolas, permitir aos estudantes um processo de observação e raciocínio, de modo que possam acompanhar a elaboração das análises com base em fatos reais da língua. Neste sentido, o estudar gramática significa um processo de construção de gramáticas, com o termo no plural, porque o aluno vai observar que não há uma única gramática da língua. A sala de aula passa a ser um laboratório, alimentado pelos dados que estão na memória dos aprendizes, visto que, via de regra, são todos falantes de português. $\mathrm{O}$ ensino de linguística nos moldes que propomos aqui permite

\footnotetext{
${ }^{1}$ Agradeço aos pareceristas deste trabalho pela leitura cuidadosa, pelos comentários e sugestões. Todos os erros remanescentes são de minha responsabilidade.
} 
ao aluno e ao professor o desenvolvimento do pensamento gramatical, da consciência linguística, que é bem diferente da mera reprodução de regras e esquemas previamente estabelecidos pela convenção da língua portuguesa, as quais limitam o aluno à memorização de conceitos e de uma metalinguagem que por si só não é muito esclarecedora.

O trabalho está organizado da seguinte forma: na seção 2 , tratamos do conhecimento explícito da língua, que deve ser aprendido pelo aluno, diferentemente do conhecimento implícito; na seção 3, apresentamos uma visão de gramática diferente da que o aluno está acostumado; na seção 4, mostramos as principais contribuições da linguística para o ensino de línguas; na seção 5, desenvolvemos a proposta de levar a linguística para dentro da escola. Por fim, fechamos o texto com algumas considerações acerca da relação direta entre a linguística e o ensino de língua portuguesa.

\section{Conhecimento explícito: o português padrão e suas variedades}

$\mathrm{O}$ aluno, quando chega à escola, já tem uma gramática da língua portuguesa adquirida ao longo da sua vivência. Todo aluno sabe, implicitamente, por exemplo, que na língua portuguesa o sintagma nominal é formado por um artigo antes do nome, como em [o carro], e não o contrário, como em [ ${ }^{*}$ carro o]. Esse mesmo aluno também sabe que as frases da sua língua são construídas com a ordem básica sujeito-verbo-objeto, como em [A Maria comprou uma casa] e não SOV como em [A Maria uma casa comprou]. Indo mais longe, verificamos que qualquer criança brasileira com dois anos, juntando um verbo com um complemento, produz enunciados como [quer leite] ao invés de [leite quer], enquanto uma criança japonesa produzirá exatamente o contrário [leite quer] e não [quer leite]. Este acerto no padrão de ordem de palavras revela que as crianças, aos dois anos, já sabem qual a ordem de palavras dentro do grupo verbal da sua língua, verbo-objeto ou objeto-verbo (COSTA; SANTOS, 2003). Contudo, as crianças não têm consciência desse conhecimento.

Costa et al. (2011, p. 7) afirmam que "o termo conhecimento explícito só faz sentido tendo como referência a ideia de que existe conhecimento implícito sobre a língua”. O conhecimento que o aluno já tem quando chega à escola é o conhecimento implícito da sua língua. Os aprendizes são falantes competentes, empregam de forma automática regras gramaticais para gerar e produzir enunciados na sua língua.

Observe o que acontece quando ouvimos uma frase simples como [Quer ler um livro?]. Nosso conhecimento fonético identifica a melodia dessa frase como uma pergunta e não uma afirmação, enquanto o nosso conhecimento morfológico permite-nos 
reconhecer o valor singular da palavra livro, pela ausência da marcação plural. Também verificamos a dependência entre os termos por meio do nosso conhecimento sintático. A construção do significado dessa simples frase vem através do nosso conhecimento semântico que nos diz o valor que o verbo querer tem nessa sentença. Além disso, por trás de uma simples frase, temos o nosso conhecimento pragmático e discursivo que nos possibilita atribuir intenções ao enunciado. O conhecimento implícito da língua é o que nos permite ativar todos estes níveis gramaticais de forma inconsciente e eficiente.

Em contraposição ao conhecimento implícito, temos o conhecimento explícito que nada mais é do que o desenvolvimento da consciência linguística dos alunos. A questão que se coloca então é como transformar a intuição linguística dos alunos e desenvolver neles a aquisição das regras da língua, o conhecimento explícito? Ou ainda, como trabalhar o conhecimento explícito em sala de aula? É neste contexto que defendemos a presença da linguística na escola, porque, como afirma Possenti (2016, s/p), "os linguistas sabem que saber gramática [...] não tem nada a ver com saber uma língua. Pode-se saber a gramática do inglês sem falar a língua e pode-se falar inglês sem saber sua gramática”. O autor ainda diz que "onde um gramático vê um erro, um linguista vê uma diferença". O que não significa que o conhecimento explícito da língua será ignorado pelo linguista.

O professor de língua portuguesa precisa levar em conta que qualquer falante de uma língua, em idade escolar, tem um conhecimento não consciente de muitas regras gramaticais. Neste caso, a atitude do professor deveria ser a de tirar proveito do conhecimento implícito dos alunos para uma explicitação desse mesmo conhecimento. O que você pensaria de um professor de educação física, por exemplo, que ignora o fato de que os alunos já correm, pulam, ou se sentam, mesmo que não tenham consciência de algumas regras para um bom uso do seu corpo? No mínimo estranho e incoerente, não é verdade? O mesmo vale - ou deveria valer - para as aulas de gramática na escola.

Basso e Pires de Oliveira (2012) observam que o aluno na escola entra em contato com uma variedade de português, a da gramática, tão diferente que é para ele outra língua, uma língua estrangeira. Os autores ressaltam que essa não é a questão, porque os falantes dominam várias gramáticas. O problema, segundo os autores, "é o professor simplesmente não se dar conta de que seu aluno está aprendendo uma segunda língua e agir como se houvesse apenas uma língua, exatamente aquela que não é a do aluno" (p. 24, grifo nosso). O professor deve trabalhar a variedade padrão ao lado das outras variedades da língua. Vamos a um exemplo prático: colocação pronominal. Ainda temos em nossa língua o uso da ênclise, como em [Empresta-me o livro], ou ainda temos o uso 
da mesóclise, como em [Emprestá-lo-ei o livro]? Por que o professor não pode trabalhar a gramática do português brasileiro e mostrar ao aluno que ela se diferencia do que está posto na gramática tradicional? A proposta é explorar o português em suas diferentes variedades.

Observe que é muito comum encontrarmos alunos no terceiro ano do ensino médio que têm dificuldades na resolução de problemas e exercícios que envolvam conhecimento de gramática, ou seja, têm dúvidas e dificuldades em realizar tarefas que demandam a explicitação de conhecimento gramatical. O ponto é que muitos professores consideram que o trabalho sobre gramática não é tão útil quanto o trabalho sobre competências de leitura, escrita, produção e expressão oral. Se esta fosse a solução para o problema, os dados do Pisa ${ }^{2}$, como mostram Basso e Pires de Oliveira (2012, p. 21), não deveriam ser tão catastróficos. Os professores devem, então, buscar uma maneira apropriada de trabalhar o conhecimento gramatical.

De acordo com Costa et al. (2011), o conhecimento explícito deve partir de um conjunto de medidas tais como: (i) investir em descrições mais adequadas da gramática; (ii) ter consciência do grau de desenvolvimento linguístico dos nossos alunos; (iii) ter consciência que alguns aspectos da língua não decorrem de uma aquisição espontânea; (iv) investir no ensino da gramática que prioriza as regularidades (vale destacar que o ensino da gramática tem enfoque na observação das exceções, esquecendo que a maior parte do que se passa nas línguas é regular); (v) orientar o estudo da gramática em dimensões para além da simples correção do erro.

Segundo Cardinaletti (2014), o conhecimento explícito não pode partir de uma gramática que é incompleta, pouco sistemática, baseada nas exceções, contendo formulações imprecisas e terminologia pouco transparente, além de não estar ancorada em uma teoria linguística coerente. Este tipo de gramática propicia o desinteresse dos alunos em relação às aulas de português. $\mathrm{O}$ professor que utiliza a gramática como um instrumento para o texto escrito tem uma visão instrumental, fortalecendo, assim, a gramática normativa que concebe a língua como um objeto perfeito, intocável. Cardinaletti (2014) afirma que as gramáticas escolares precisam incorporar os resultados da pesquisa linguística contemporânea, a fim de despertar no aluno o interesse pela sua própria língua.

\footnotetext{
${ }^{2}$ A sigla Pisa significa Programa Internacional de Avaliação de Alunos (em inglês, Programme for International Student Assessment). Basso e Pires de Oliveira (2012) observam que, em 2009, o desempenho dos alunos brasileiros nos testes internacionais de leitura aplicados pelo Pisa mostra uma situação preocupante, o Brasil ficou acima de apenas 12 países dentre os 66 países envolvidos no teste. Em 2015, o Pisa testou cerca de 540 mil estudantes de 15 anos de idade de 72 países. O Brasil ocupou a 59a posição em leitura, ficando acima apenas de 13 países. É possível verificar que a situação em relação ao desempenho dos estudantes brasileiros quanto à leitura mudou quase nada de 2009 para cá.
} 
Também Duarte (2008) aborda o desenvolvimento da consciência linguística através do método científico e do treino do pensamento analítico. Para a autora, as etapas do pensamento científico adaptadas ao ensino e à aprendizagem do conhecimento explícito da língua envolvem: descrever minuciosamente os dados, observar esses dados; formular hipóteses; testar essas hipóteses; validar ou refutar essas hipóteses; exercitá-las e, finalmente, avaliar a aprendizagem realizada.

O ensino da linguística na escola permite aos alunos descobrirem o funcionamento de um fenômeno gramatical por meio de uma perspectiva reflexiva e consciente da língua. $\mathrm{O}$ professor torna-se o organizador e o mediador entre os conhecimentos a adquirir e o aluno. A questão em jogo é a não exclusão da gramática, o desafio passa a ser o de "construir gramáticas para se apoderar da metalinguagem, aprendê-la e sabê-la”, como afirmam Basso e Pires de Oliveira (2012, p. 23). Consideramos importante o ensino da norma culta, da língua escrita, mas de forma que este ensino esteja pautado na gramática do português brasileiro e não na "sintaxe lusa" (NOLL, 2008).

\section{Uma visão diferente de gramática}

O estudo da gramática que propomos aqui é importante para resgatar a autoconfiança linguística do aluno. É importante buscar uma forma de trabalho que extinga ou, pelo menos, diminua o desinteresse do aluno pelas aulas de língua portuguesa. A proposta é trazer a linguística para dentro da escola no sentido de dar ao aluno e ao professor um olhar científico sobre a nossa língua, possibilitando tratá-la como um objeto natural, que merece um estudo sistemático e não meramente prescritivo.

A abordagem de gramática que defendemos neste trabalho já está colocada nos documentos ministeriais da educação em Portugal (XAVIER, 2012), os quais tratam do conhecimento explícito da língua com enfoque na linguística contemporânea, como se deduz facilmente em algumas sugestões dos Programas de Português do Ensino Básico, explicitadas no Conhecimento da Língua: Desenvolver a Consciência Linguística (DUARTE, 2008) e no Guião de Implementação dos Programas de Português - Conhecimento Explícito da Lingua (COSTA et al., 2011), que servem de apoio aos Programas. Infelizmente, a situação não é a mesma no Brasil, visto que "os Parâmetros Curriculares Nacionais, em boa medida, excluem a gramática, que só deve ser utilizada como instrumento para o texto escrito" (BASSO; PIRES DE OLIVEIRA, 2012, p. 23).

A questão principal é introduzir o conteúdo gramatical de forma consciente, sistemática e crítica. Não é o ensinar gramática nos moldes que já é feito na escola, menos ain- 
da o aplicar gramática ao texto, mas o construir gramáticas (insistimos no termo plural!). É aqui que a linguística entra como matéria de ensino comparada à física, matemática, química, biologia, entre outras ciências. Basso e Pires de Oliveira (2012, p. 27) afirmam que a linguística permite que as "aulas de português tenham um direcionamento totalmente diferente do que normalmente vemos, em particular, porque permite que o professor de português se liberte da prisão de ter como única função ensinar a escrever e a ler”.

As aulas de gramática desde muito cedo devem (i) propiciar ao aluno uma perspectiva reflexiva e consciente da língua, (ii) suscitar o espírito de investigação, de curiosidade e de questionamento frente à linguagem que ele emprega no seu dia a dia, (iii) desenvolver a aprendizagem das principais estruturas e dos mecanismos fundamentais da língua, e devem, ainda, (iv) permitir a abordagem do tipo experimental. ${ }^{3}$ Por que não um laboratório de gramática na escola? Um espaço em que o professor e o aluno possam observar, testar, analisar os dados da língua, incluindo todas as variedades do português brasileiro. Um espaço que possibilite maior reflexão sobre o conhecimento explícito trabalhado nas aulas de língua portuguesa.

É claro que um laboratório de gramática não equivale a atividades de monitoria da disciplina ou a aulas de reforço. Também não faz sentido pensar em um laboratório de gramática quando nas aulas de língua portuguesa o professor não tem um olhar crítico e consciente acerca das diferentes regras, diferentes gramáticas. O laboratório está longe de ser um espaço de resolução de exercícios de fixação de metalinguagem, o que já é feito em muitas escolas. A proposta, fundamentada em Pires de Oliveira e Quarezemin (2016), é o exercício do raciocínio gramatical, como bem observado por Ataliba Castilho no prefácio do livro das autoras, Gramáticas na escola: espera-se com essa abordagem de gramática levar o professor e o aluno "a ultrapassar o entendimento pedestre de que as gramáticas são livros que enumeram regras de uso da língua, nem sempre compreensíveis, porque não fundamentadas numa teoria explícita sobre as línguas naturais” (CASTILHO, 2016, p. 13).

A proposta é manter o fascínio pela língua, despertar a curiosidade do aluno e a vontade de aprender as regras explícitas da língua. O aprendiz precisa observar, refletir, desconstruir e construir novamente a metalinguagem que aparece na gramática tradicio-

\footnotetext{
3 A Università Ca' Foscari de Veneza/Itália tem um programa de física voltado para as crianças do ensino fundamental, visando o desenvolvimento do raciocínio lógico desde muito cedo. Neste programa, alguns professores da universidade apresentam para as crianças fenômenos físicos, como a solidificação da água, por exemplo, a fim de criar um laboratório experimental e interativo. Veja que a ideia principal é estimular a curiosidade das crianças, fazer com que reproduzam desde cedo o passo a passo da investigação científica: observar, descrever, hipotetizar, testar, analisar. Tudo isso de uma forma simples e elucidativa. A pergunta que fica é: por que não podemos fazer o mesmo com os fenômenos gramaticais da nossa língua?
} 
nal para poder se apoderar dela. O problema em si não é o emprego da metalinguagem, mas a forma como ela aparece nas aulas de língua portuguesa. Os alunos normalmente relacionam a metalinguagem a uma lista a ser decorada; quando, na verdade, ela precisa ser compreendida. Temos noção de que alguns professores já problematizam as definições incoerentes da gramática tradicional, mas o ponto deste estudo não é este. $\mathrm{O}$ aluno deve aprender a gramática da escrita, mas a partir de uma nova perspectiva científica/ naturalista ${ }^{4}$ a da linguística.

Esta nova perspectiva sobre as línguas vai de encontro com a gramática tradicional/normativa e com o ensino prescritivo sobre as línguas. $O$ ensino pautado apenas na gramática escrita da língua iguala o conhecimento linguístico com as habilidades de leitura e escrita. Perini $(2006,2010,2016)$ observa que é essencial desenvolver um tipo de pensamento lógico, coerente e adequado aos fatos observados - e acima de tudo claro e compreensível. Quarezemin (2017) destaca que a análise gramatical deve fazer sentido, de nada adiantam definições gramaticalmente vagas, irrelevantes ou obscuras. A autora ainda verifica que, infelizmente, encontramos na gramática escolar definições empiricamente inadequadas, como, por exemplo, dizer que "o presente designa um fato ocorrido no momento em que se fala", quando sabemos que a frase [Ana estuda] em PB não exprime algo que se passa no momento da fala, como em [Ana está estudando]. Uma sentença como [Ana estuda] equivale a um evento habitual.

Na tentativa de mostrar outra rota de abordagem da língua e da gramática vamos tratar na próxima seção de algumas contribuições da linguística contemporânea e de como o aluno pode formular suas próprias hipóteses sobre a língua, comportamento que possibilita o raciocínio gramatical, o pensamento lógico nos termos de Perini (2010, 2016), Castilho (2010) e Pires de Oliveira e Quarezemin (2016).

\section{As contribuições da Linguística para o ensino de línguas}

De acordo com Cardinaletti (2014), as principais aquisições da pesquisa linguística contemporânea podem ser resumidas a partir das noções de sintagma, hierarquia e movimento. A linguística mostrou que a frase não é uma simples sequência de palavras desconexas, já que as palavras são organizadas em unidades sintáticas até formarem uma

\footnotetext{
${ }^{4}$ Pires de Oliveira et al. (2013, p. 16-17) acentuam que a perspectiva científica "tem efeitos positivos na aprendizagem não apenas da ciência, porque aprendemos a construir modelos científicos com um material que é facilmente acessível - as nossas interações linguísticas cotidianas e o conhecimento implícito que todos temos das regras da nossa língua (regras internalizadas) -, mas também no desenvolvimento da escrita e da leitura, porque permite que o aluno saiba manipular diferentes gramáticas, e aprenda que há diferentes línguas intermediárias, estágios na aprendizagem de uma outra língua”.
} 
unidade máxima, a sentença. A análise científica das línguas também mostrou que a organização da frase é hierárquica: cada unidade sintática constitui um bloco dentro de uma estrutura hierarquicamente organizada. Outro avanço da linguística foi a descoberta de que as regras se aplicam ao sintagma, não à sequência de palavras que não formam uma unidade, sendo que os sintagmas podem se mover e aparecer em posições diferentes daquela que seria esperada.

Um simples teste de pronominalização, como vemos em (1), mostra que o pronome substitui o sintagma e não apenas uma palavra, o que indica a incoerência de estudar a formação das frases do ponto de vista da combinação de palavras, como unidades soltas.

(1) a. A irmã da Maria viajou.

b. *A ela da Maria viajou. ${ }^{5}$

c. Ela viajou.

O pronome ela deve substituir todo o sintagma nominal [a irmã da Maria] e não apenas o substantivo [irmã]. Observe que dentro desse sintagma temos outro constituinte nominal, sabemos disso porque conseguimos formar o sintagma [a irmã d[ela]].

As regras de movimento vão se aplicar ao sintagma e não à palavra isolada, como verificamos por meio das sentenças clivadas em (2) e da topicalização em (3).

(2) a. Foi a irmã da Maria que viajou.

b. *Foi a irmã que da Maria viajou.

(3) a. A irmã da Maria, ela viajou.

b. *A irmã, da Maria ela viajou.

Em (2), não podemos colocar parte de sintagma entre o verbo ser e o complementizador ${ }^{6} q u e$, como mostra a agramaticalidade de (2b). Isto ocorre porque o movimento deve ser de todo o sintagma, como observamos pela boa formação da sentença (2a). $O$ teste da topicalização (que vemos em 3) consiste em mover um sintagma para o início da frase, destacando esse constituinte dos demais elementos. A topicalização pode vir acompanhada do pronome que recupera o sintagma deslocado (3a). A agramaticalidade de (3b) decorre da impossibilidade de deslocar apenas uma parte do sintagma.

\footnotetext{
${ }^{5} \mathrm{O}$ sinal * indica que a frase não é gramatical do ponto de vista sintático; enquanto o sinal \# indica que a frase, ainda que sintaticamente bem formada, tem algum problema de interpretação. $O$ teste aplicado ainda mostra a inadequação de definir pronome como "aquele que substitui o nome", uma definição típica de pronomes pessoais nas gramáticas normativas (CEGALLA, 1996, por exemplo).

${ }^{6} \mathrm{O}$ termo complementizador é usado em referência ao elemento que que também aparece nas sentenças encaixadas/subordinadas do tipo [João disse que a Maria viajou].
} 
Outro caso que nos permite observar a composição hierárquica, não linear, de uma sentença diz respeito às chamadas expressões idiomáticas (as quais aparecem em número elevado no português brasileiro). ${ }^{7}$

(4) a. Carlos [bateu as botas].

a. \#A pedra bateu as botas.

b. O tenista Guga [pendurou as chuteiras].

b. \#A criança pendurou as chuteiras.

Essas sentenças evidenciam que primeiro ocorre a formação do predicado [verbo + complemento] para, em seguida, entrar outro sintagma na frase, que deve ser compatível com as propriedades semânticas deste predicado. O termo [bater as botas] é usado quando designa a morte de alguém. Acontece que morrer pressupõe um ser mais animado, podendo ser humano, animal, vegetal, mas deve ter animacidade. Observe que o mesmo vale para o exemplo (b). A composição [pendurar as chuteiras] equivale a se aposentar, deixar de exercer uma atividade que já vinha sendo feita há muito tempo. Por isso, a impossibilidade de selecionar [a criança] como alguém que tenha se aposentado, visto que o sintagma [a criança] faz alusão a alguém que ainda não tenha idade suficiente para se aposentar. Se a frase fosse uma combinação aleatória de itens lexicais e não respeitasse nenhuma hierarquia, não seria esperado o estranhamento nas sentenças (a') e (b'). Veja que quando mudamos o predicado, as sentenças ( $\left.a^{\prime}\right)$ e ( $\left.b^{\prime}\right)$ são perfeitamente possíveis.

(5) a. A pedra bateu na janela.

b. A criança pendurou o vestido.

Os exemplos sugerem que há uma relação estreita entre o verbo e o complemento, mais forte do que a relação entre o sujeito e o predicado (OTHERO, 2014). Ainda em se tratando do predicado verbal e da seleção dos sintagmas que o acompanham para formar uma sentença ${ }^{8}$, outra contribuição importante da linguística diz respeito à seleção semântica dos constituintes pelo verbo, denominada na linguística de seleção temática. Um tópico que pode ser abordado em sala de aula para que o aluno observe a interface sintaxe-semântica. Aqui verificamos mais uma vez a hierarquia dos constituintes na frase,

\footnotetext{
${ }^{7}$ Em conferência realizada no II Congresso de Ensino de Português Brasileiro na Universidade Italiana, em junho de 2017, na Itália, Mário Perini afirmou já terem sido catalogadas mais de 8600 expressões idiomáticas no português brasileiro. O resultado desta catalogação pode ser visto no Dicionário de Expressões Fixas e Idiomáticas, de Lúcia Fulgêncio (no prelo).

${ }^{8}$ A linguística formal emprega o termo argumentos para designar os sintagmas que acompanham o verbo na sentença. $\mathrm{O}$ complemento que está à direita do verbo é chamado de argumento interno, enquanto o sintagma que figura à esquerda do verbo é denominado argumento externo. O leitor interessado neste assunto pode consultar Mioto et al. (2013).
} 
não uma simples composição linear entre palavras. A linearidade da sentença fica restrita à superficialidade. Vejamos o conjunto de frases abaixo:

(6) a. O Pedro parece sorrir. a'. O Pedro deseja sorrir.

b. A flor parece flutuar. b. \#A flor deseja flutuar.

c. A alegria parece ter fim. c. \#A alegria deseja ter fim.

d. Parece chover em Floripa. d. * Deseja chover em Floripa.

A partir da observação desses dados, o aluno vai perceber que o verbo parecer é mais flexível quanto aos elementos que se combinam com ele do que o verbo desejar. $\mathrm{Na}$ linguística, dizemos que o verbo parecer não impõe restrição semântica ao sintagma que pode acompanhá-lo na frase, tanto que temos um constituinte [+humano, + animado] em (a) - [O Pedro], um constituinte [-humano, +animado] em (b) - [A flor], um sintagma

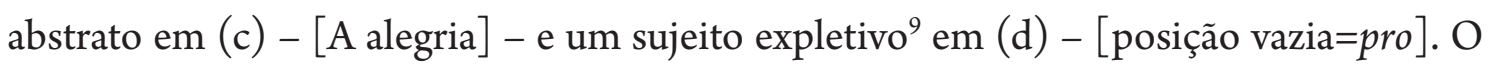
verbo desejar, ao contrário, impõe restrição semântica sobre o elemento que o acompanha, a única sentença bem formada sintática e semanticamente é (a').

Observe o que acontece quando trocamos o complemento que segue o verbo parecer nas sentenças (6a) e (6b).

(7) a. \#O Pedro parece ter fim.

b. \#A flor parece sorrir.

Agora temos sentenças estranhas do ponto de vista semântico-pragmático, já que o evento de ter fim não se refere a uma pessoa, assim como sorrir não se combina com o sintagma a flor. O que isso pode nos indicar? A seleção semântica dos sintagmas que aparecem à esquerda do verbo parecer é realizada pelo predicado que o segue, não pelo próprio parecer. O contrário ocorre com o verbo desejar que seleciona diretamente os seus constituintes, como verificamos pela impossibilidade das sentenças do grupo linha em (6); a única seleção possível é do sintagma [O João], que é [+humano, +animado]. Em contato com dados dessa natureza nas aulas de gramática, o aluno tem condição suficiente para formular hipóteses sobre a combinação entre os elementos na frase, por exemplo. Esse é um processo de construção de conhecimento gramatical, não de recepção passiva de conteúdo gramatical pronto. $\mathrm{O}$ aluno ainda pode verificar que os verbos parecer e desejar não devem pertencer à mesma classificação.

\footnotetext{
${ }^{9}$ O sujeito ou pronome expletivo é um elemento que tem efeito sintático na frase, mas não tem realização fonética/morfológica no português brasileiro (PB), contrário ao inglês ou francês, por exemplo, em que esse sujeito aparece realizado, como em It rains e Il pleut (Chove), respectivamente. Os pronomes it do inglês e $i l$ do francês correspondem ao sujeito expletivo pro do PB. Sobre esse assunto ver Raposo (1992).
} 
Infelizmente, o ensino da gramática que desconsidera as contribuições da linguística contemporânea é apresentado de forma maçante e sem reflexão crítica sobre a língua do aluno, da gente $!^{10} \mathrm{O}$ resultado disso é ruim, pois os alunos decoram uma série de listas e nomes, mas não conseguem compreender o que está por trás daquela terminologia. Como já apontado por Quarezemin (2016a, p. 211),

não há um método acabado para trabalhar os conteúdos gramaticais em sala de aula, é preciso despertar a curiosidade dos alunos, torná-los agentes do processo de aprendizagem. É necessário fazer com que os alunos reflitam sobre a língua e consigam construir, junto com o professor, teorias para a compreensão do fenômeno. $\mathrm{O}$ aluno deve sim formular hipóteses sobre os fenômenos gramaticais e testar suas hipóteses em parceria com o professor da disciplina de Língua Portuguesa.

A realidade das aulas de língua portuguesa ainda é muito voltada ao ensino enquanto transmissão de conhecimento gramatical acabado, por vezes idealizado. Contra esse tipo de postura Pires de Oliveira (2016, p. 157) é enfática ao afirmar que

[...] refletir sobre a natureza, sobre as línguas, é superinteressante! Se a escola não consegue mostrar isso, então é preciso mudar a escola urgentemente. As línguas naturais são muito instigantes e a Linguística é a disciplina que busca entender como elas são. Nossa proposta é que as aulas de língua sejam investigativas em primeiro lugar, que o aluno seja $o$ detetive, que ele se aventure, juntamente com o professor e os colegas em um trabalho colaborativo, a construir gramáticas, que nada mais são do que maneiras de refletirmos sobre as línguas.

\section{A Linguística dentro da Escola}

Vimos acima que a entrada da linguística na escola permite ao professor de português trabalhar o raciocínio científico junto com os seus alunos. Nessa perspectiva, refletir sobre linguagem requer apenas um bom professor, quadro negro e a intuição dos alunos. A linguística na escola permite a inclusão de todos os falantes, não está centrada apenas na variedade padrão do português, pois traz à tona as variedades que são estigmatizadas socialmente (QUAREZEMIN, 2016b). Em 1995, Mário Perini, na sua Gramática Descritiva do Português, propõe que o ensinar gramática deve corresponder ao ensino do raciocínio científico, à construção de modelos científicos. Infelizmente, essa visão de gramática, de refletir uma língua, não aparece nos Parâmetros Curriculares Nacionais do Ensino Fundamental (PIRES DE OLIVEIRA; QUAREZEMIN, 2016).

\footnotetext{
${ }^{10}$ Uma boa indicação de leitura sobre o "português da gente" é o livro de Ilari e Basso (2006). Um olhar de dois importantes linguistas sobre as origens e a história do português brasileiro, a organização interna da nossa língua, o modo como falamos e as variações da língua.
} 
Segundo Xavier (2009), quanto mais cedo a reflexão sobre a língua for trabalhada no percurso escolar, as atividades em sala de aula transcorrerão com maior naturalidade e sucesso. As aulas de língua portuguesa farão sentido para os alunos quando o professor conseguir despertar a curiosidade e o entusiasmo sobre a sua língua (não a língua de outrem). Um alerta aos professores de ensino fundamental! A autora afirma que os ganhos em longo prazo são inquestionáveis, uma vez que quem descobre dificilmente esquece. Além disso, o ensino de gramática que parte da descoberta forma alunos críticos, com espírito de grupo e desenvolvimento de discurso argumentativo.

Quais serão, então, as etapas de uma aula de gramática que aposte no desenvolvimento do pensamento lógico/científico? Nesta seção vamos exemplificar com dados do português brasileiro (PB) como o professor pode orientar os alunos nessa empreitada. O processo de construção de conhecimento gramatical deve envolver: (i) observação de um fenômeno; (ii) descrição dos dados; (iii) manipulação dos dados e formulação de hipóteses; (iv) testagem das hipóteses (a verificação); (v) formulação de regras, partindo das regularidades; (vi) prática de exercícios.

Cabe destacar que é necessário adotar uma metalinguagem comum à turma, reavaliando e redefinindo, por vezes, a metalinguagem gramatical. Os professores não devem ter receio de introduzir o mais cedo possível, e sempre que necessário, a metalinguagem nas suas aulas. Observe que substituir a terminologia "prefixo" e "sufixo" por "pedacinho de palavra" não contribui para a aquisição e o desenvolvimento da metalinguagem e da competência linguística dos alunos. O problema não está centrado no emprego da metalinguagem tradicional, mas no modo como essa metalinguagem é trabalhada com os alunos. Imagine um professor de química ou física explicar determinados fenômenos sem denominá-los. É no mínimo estranho trabalhar o conteúdo gramatical sem recorrer aos termos básicos sujeito, verbo, objeto, predicado, substantivo, adjetivo, entre outros. O problema está no fato de o aluno não entender a função que esses elementos desempenham no sistema linguístico.

É claro que o foco das aulas de gramática não deve estar na etiquetagem, mas no exercício de conseguir descrever um fenômeno para avaliar as possibilidades gramaticais da sua língua. $O$ estudo gramatical deve partir da sintaxe para os demais componentes da gramática, não deve partir de listas e/ou palavras isoladas (XAVIER, 2009). Quando o aluno é chamado para resolver problemas, torna-se um elemento ativo do processo de ensino e aprendizagem. A construção de gramáticas muitas vezes coloca o aluno em confronto com uma situação problemática, despertando a curiosidade desse aluno a ponto 
de tentar resolvê-la. É como se o aluno estivesse diante de um quebra-cabeça sobre o funcionamento da sua própria língua.

Quando a turma está na fase da observação de um fenômeno linguístico, em contato com dados da língua, é importante que o professor lance algumas questões como, por exemplo, perguntar se é possível retirar ou substituir algum elemento sem tornar a sentença agramatical; se sim, quais as consequências para a frase?; o que acontece quando algum elemento é movido na sentença, a frase ainda é gramatical?. Observe que o professor estará manipulando os dados junto com os alunos, sem apresentar o conteúdo gramatical como um objeto pronto, acabado.

Desde muito cedo é possível trabalhar com essa metodologia de construção de gramáticas. Logo no início do ensino fundamental, o aluno é capaz de verificar que nada acontece na sentença quando um artigo é substituído por um demonstrativo. Vejamos:

(8) a. Pedro comprou o/um livro infantil.

b. Pedro comprou esse/este/aquele livro infantil.

Ao observar essa substituição, a partir de um conjunto representativo de dados, os alunos podem, com a orientação do professor, formular a hipótese de que esses itens lexicais pertencem à mesma classe de palavras porque ocupam o mesmo lugar na frase. Depois de testar/verificar essa hipótese, os alunos podem criar uma regra sobre classe de palavras, por exemplo.

O professor pode avançar na discussão e perguntar aos alunos se o sintagma [o livro infantil] tem o mesmo valor semântico de [um livro infantil]. E se o aluno formar a frase Pedro comprou livro infantil, sem a presença de qualquer artigo, essa sentença é possível no PB? Podemos tirar o artigo da frente do nome sem prejudicar a compreensão da frase? Observe que é possível dizer algo como Pedro ouviu criança chorar ou Pedro quer sorvete, mas tendemos a não aceitar as frases Pedro limpou jardim, Ana escreveu carta ou Menino gosta de pizza. O que está por trás disso? ${ }^{11} \mathrm{O}$ professor ainda pode deslocar o adjetivo infantil para o início da frase, como em (9), e ver a reação dos alunos.

(9) *Infantil Pedro comprou o/um livro.

Se o adjetivo pertence ao sintagma nominal [o/um livro], não poderá se mover sozinho. Assim como não é possível mover [o/um livro] e deixar o adjetivo sozinho no final da frase, como em (10).

${ }^{11}$ Sobre a semântica dos nomes sem artigos, os chamados nominais nus, ver Pires de Oliveira e Mezari (2012). 
$(10) * \mathrm{O} / \mathrm{um}$ livro Pedro comprou infantil.

Parece, então, que o adjetivo que especifica/determina um nome, tradicionalmente chamado de adjunto adnominal, não pode ser separado desse nome por algum tipo de movimento. Mas algo diferente acontece quando o adjetivo tem outra função sintática, agora essa separação é possível, como verificamos em $(11 \mathrm{~b}, \mathrm{c})$.

(11) a. Pedro conheceu a menina maquiada.

b. A menina Pedro conheceu maquiada.

c. Maquiada Pedro conheceu a menina.

$\mathrm{O}$ adjetivo maquiada nas frases acima tem a mesma função do adjetivo infantil em (8)? Parece que o termo maquiada não necessariamente pertence ao sintagma nominal [a menina], podendo ocorrer isolado. Neste caso, a interpretação da sentença é a de que Pedro conheceu a menina quando (no dia em que) ela estava maquiada. $\mathrm{O}$ aluno também pode verificar que o adjetivo maquiada também pode, neste caso, determinar uma característica inerente à menina, diferenciando-a no conjunto de meninas. Neste caso, a interpretação é a de que Pedro conheceu a menina queé (está sempre) maquiada. Se esta sentença tem duas interpretações, é possível afirmar que temos um caso de ambiguidade sintática (que é diferente da ambiguidade lexical, por exemplo, a palavra manga pode se referir à fruta ou à parte da roupa). Observe que é muito comum nas línguas naturais o fato de uma sentença ter duas interpretações distintas, ainda que a ordem linear das palavras seja a mesma. ${ }^{12}$ A partir disso, o grupo pode formular a hipótese de que quando o adjetivo pertence ao sintagma nominal exerce a função de adjunto; e quando não pertence ao sintagma nominal exerce outra função sintática, a de predicativo. Claro que o professor já terá tratado da noção de sintagma (vimos na seção acima que é uma noção crucial para o ensino da sintaxe).

$O$ professor ainda pode sugerir a troca por outros adjetivos e ver o que acontece na frase, usar, por exemplo, o adjetivo inteligente. Será que temos ambiguidade na frase Pedro conheceu a menina inteligente? Será que o adjetivo inteligente é do mesmo tipo do adjetivo maquiada? Podemos dizer algo do tipo Inteligente Pedro conheceu a menina ou então $A$ menina Pedro conheceu inteligente? Parece que não. Algo que também indica que os dois adjetivos não são do mesmo tipo semântico, maquiada pode indicar um estado, enquanto o adjetivo inteligente não. Uma pessoa não pode estar inteligente hoje e amanhã não mais;

12 Basta pensar em frases simples como João viu a menina de binóculos, Pedro recebeu um cartão postal de Florianópolis, $O$ professor presenteou os alunos com notas altas, Carlos bateu na velha de bengala. Sobre ambiguidade sintática ver Mioto et al. (2013). 
ou você é inteligente ou não é! O mesmo não ocorre com um adjetivo do tipo maquiada: posso estar maquiada hoje e no outro dia não. Que hipótese o aluno pode formular a partir disso? Uma hipótese possível é a de que os adjetivos que indicam estado podem exercer duas funções sintáticas nas sentenças, de adjunto e/ou de predicativo, enquanto os adjetivos que não indicam estado só exercem a função de adjunto nominal.

A manipulação de dados de um corpus permite formular hipóteses descritivas ou explicativas sobre o funcionamento dos fenômenos linguísticos (DUARTE, 2008; COSTA et al., 2011; PIRES DE OLIVEIRA; QUAREZEMIN, 2016). As hipóteses elaboradas são testadas e se se confirmarem gerais e regulares, poderão se transformar em regras. Infelizmente, a abordagem tradicional de ensino de gramática já começa nesta última etapa. Ao contrário de uma metodologia que parte do princípio da construção de conhecimento, o foco está centrado no professor que é quem apresenta as regras, ou seja, transmite o conteúdo pronto, sem espaço para a construção, a elaboração. Por outro lado, quando o professor trabalha levando em conta o aluno como participante ativo no processo de construção do conhecimento gramatical, a turma sistematiza o conhecimento em conjunto com o professor que está ali para orientá-los.

Os alunos podem se dividir em grupos e formularem diferentes regras; em seguida, pode ser feita uma comparação entre os grupos; com a ajuda do professor a turma pode organizar com precisão e rigor as regras possíveis que norteiam a descoberta feita. Depois disso, os alunos comparam as regras que criaram com o que as gramáticas de referência indicam. Nesse sentido, é importante haver diferentes tipos de gramáticas na aula de língua portuguesa, como defendido por Pires de Oliveira e Quarezemin (2016). Quando não se considera apenas a gramática tradicional/normativa, constata-se que o mesmo fenômeno pode ser descrito de forma diferente, segundo a gramática consultada.

Outro ponto que pode ser explorado pelo professor de gramática diz respeito às construções inovadoras que encontramos no português brasileiro. Não estamos nos referindo a construções linguísticas encontradas em textos escritos, mas a dados que já estão até em campanhas publicitárias, como verificamos no exemplo abaixo, apresentado por Negrão e Viotti (2014, p. 317):

(12) A cada minuto quatro coisas vendem.

Qual o sujeito desta frase? Este tipo de sentença foge ao padrão regular do PB em que o sujeito normalmente é expresso por um constituinte mais animado. Será que esta sentença pode ser comparada às construções chamadas de tópico-sujeito, como em 
$(13)^{13}$, ou comparada às sentenças com alternância sintática, como em (14)?

(13) a. Essa sala bate sol.

b. O carro furou o pneu.

(14) a. O navio afundou.

b. A porta abriu.

Observe que as sentenças em (13) são originadas a partir de (15), enquanto as sentenças em (14) têm como contraparte as sentenças em (16).

(15) a. Bate muito sol nessa sala.

b. Furou o pneu do carro.

(16) a. O inimigo afundou o navio.

b. João abriu a porta.

A partir dos dados, é possível formular a hipótese de que a posição sujeito no $\mathrm{PB}$ é flexível e aceita constituintes de natureza diversas. Os exemplos em (15) permitem ao aluno verificar que um sintagma locativo (13a) e um sintagma possessivo (13b) ocorrem na posição pré-verbal. O aluno também pode observar que as sentenças em (14) apresentam outro tipo de sintagma na posição do sujeito, nesses casos, o complemento é que foi movido para essa posição, como mostram os exemplos em (16). Além dessas sentenças, também encontramos na gramática do PB as construções em (17), apresentadas por Avelar e Galves (2013, p. 113):

(17) a. As crianças estão nascendo o dentinho.

b. Os carros acabaram a gasolina no meio da viagem.

Agora temos sintagmas possessivos na posição de sujeito acionando a concordância com o verbo. Este tipo de concordância parece não ocorrer em outras línguas românicas, como o português europeu, por exemplo. Em italiano, Quarezemin e Cardinaletti (2017) verificam que o movimento do possessivo para a posição de sujeito é realizado por meio de um sintagma preposicionado dativo, acompanhado da preposição $a$, mas a concordância não é acionada.

(18) a. Al bambino sta nascendo un dentino.

(À criança está nascendo um dentinho)

${ }_{13}$ Exemplos retirados de Pontes (1987) que foi quem deu início ao estudo das construções denominadas pela autora de tópico-sujeito. 
b. Alla macchina si è bucata una gomma.

(Ao carro (se) furou um pneu)

A comparação dos dados em (17) e (18) mostra que as duas línguas aceitam o preenchimento da posição sujeito por constituintes que normalmente desempenham outras funções sintáticas na sentença. As autoras acima citadas observam que o constituinte que corresponde ao sintagma preposicionado dativo do italiano é realizado como um sintagma nominal em PB. A comparação com o italiano nos permite verificar que outras línguas românicas também projetam constituintes de natureza diversa para a posição sujeito, essa não é uma característica restrita ao $\mathrm{PB}$, o que coloca em xeque a associação dessa língua às línguas de proeminência de tópico (QUAREZEMIN; CARDINALETTI, 2017; COSTA, 2010).

O aluno vai compreender com dados dessa natureza que a definição de sujeito da gramática tradicional é muito simplista e precisa urgentemente ser reformulada. Também vai verificar que o sujeito sintático, aquele que ocupa a posição pré-verbal e concorda com o verbo, pode não corresponder ao sujeito semântico, aquele que está diretamente envolvido no evento descrito pelo verbo da sentença, que apresenta as propriedades requeridas pelo evento.

Voltando ao exemplo (12), A cada minuto quatro coisas vendem, está claro que o sintagma [quatro coisas] desencadeia a concordância do verbo vender, sendo assim é o sujeito sintático da frase. Mas e quanto ao sujeito semântico? Afinal de contas o verbo vender pressupõe como sujeito alguém que possa executar a atividade de venda, um sintagma [+humano, +animado]. Observe que essa sentença, no contexto publicitário em que foi usada, não corresponde a uma passiva analítica do tipo $A$ cada minuto quatro coisas são vendidas (por alguém), nem mesmo a passiva sintética como $A$ cada minuto se vende $(m)$ quatro coisas. Negrão e Viotti (2014) afirmam que este tipo de sentença representa um alto grau de impessoalização, diferentemente das sentenças com alternância que aceitam a inserção do pronome se, como em $A$ porta se abriu, ou a formação passiva, como em $A$ porta foi aberta pelo Pedro. As autoras observam que este tipo de sentença não pode ser associada à perda do pronome se em $\mathrm{PB}^{14}$, diferentemente do que ocorre com as sentenças com sintagma locativo em posição de sujeito. ${ }^{15}$

\footnotetext{
${ }^{14}$ Negrão e Viotti (2014) argumentam que essas construções resultam do contato que o português clássico teve com o quimbundo nos séculos coloniais.

15 Sobre a concordância entre o sintagma locativo e o verbo ver os trabalhos de Avelar (2009), Avelar e Cyrino (2008), Avelar e Galves $(2011,2013)$. Para um tratamento diferente do locativo preposicionado e do sintagma nominal locativo ambos em posição de sujeito ver Quarezemin (2017) e Quarezemin e Cardinaletti (2017).
} 
(19) a. No hospital contrata enfermeiras.

b. No hospital contrata-se enfermeiras.

Uma questão que poderia ser tratada com os alunos é se o sintagma locativo preposicionado em (19a) tem o mesmo comportamento do sintagma nominal sem a preposição, como em (20). Ainda podemos questionar se há concordância entre o locativo e o verbo contratar em (19a).

(20) O hospital contrata enfermeiras.

Observe que a sentença (20) não aceita a inserção do pronome se, como mostra a agramaticalidade de (21a); e também não aceita a falta de concordância, como vemos em (21b), que é o oposto de (21c).

(21) a. ${ }^{*} \mathrm{O}$ hospital contrata-se enfermeiras.

b. ${ }^{*} \mathrm{O}$ hospital contratam enfermeiras.

c. No hospital contratam enfermeiras.

A sentença (21c) sugere uma resposta negativa para a pergunta feita acima, se há concordância entre o locativo e o verbo contratar em (19a), diferentemente do sintagma nominal locativo [o hospital] que exige o estabelecimento da concordância. Vejamos o que acontece quando os sintagmas pré-verbais estão no plural.

(22) a. Nos hospitais contrata enfermeiras.

b. Nos hospitais contratam enfermeiras.

c. Nos hospitais contrata-se enfermeiras.

As sentenças $(22)^{16}$ representam uma forma de impessoalização, quando não sabemos quem é o sujeito da frase, como se tivesse ali um sujeito genérico não realizado. A aceitabilidade de (22a) pelos falantes do PB sinaliza que a concordância não ocorre necessariamente com o sintagma locativo. $\mathrm{O}$ comportamento oposto é verificado com o sintagma nominal [os hospitais] que de fato exerce a função do sujeito sintático da frase, ainda que não seja do tipo [+animado]. Negrão e Viotti (2008, p. 188) afirmam que, quando "o referente é uma instituição, é possível preservar pelo menos algumas de suas características de agentividade e controle". Tanto o locativo preposicionado [no hospital] quanto o locativo nominal [o hospital] nos exemplos acima têm a função de sujeito nas sentenças, mas somente o último realiza a concordância com o verbo.

${ }^{16} \mathrm{Um}$ dos pareceristas deste trabalho ressalta que a sentença (19a) não faz parte do seu dialeto e julga a sentença (22a) como não gramatical. Esse parecerista aponta a variação linguística como mais uma propriedade da linguagem que pode ser explorada nas aulas de língua portuguesa. 
Observe que a reflexão sobre a língua do aluno, não sobre uma gramática em desuso, pode ajudá-lo a compreender fenômenos gramaticais que vistos de forma isolada não fazem muito sentido. Ainda que essas questões não sejam diretamente tratadas no vestibular, que acaba sendo a grande preocupação dos alunos, professores, pais e diretores da escola, o professor de gramática pode direcionar o conteúdo "cobrado" a essa forma de exposição. Este professor deve introduzir o pensamento científico em suas aulas, possibilitando que seus alunos construam gramáticas de diferentes línguas, incluindo a gramática da escrita, da fala vernacular, da língua do dia a dia, até mesmo da língua de sinais, uma vez que pode haver alunos surdos nas turmas.

\section{Fechando algumas pontas...}

Ainda que saibamos que a linguística não entra nas escolas como uma disciplina isolada, acreditamos que os professores de língua portuguesa podem trabalhar em sala de aula fenômenos linguísticos que propiciem a reflexão da língua enquanto objeto de estudo. Também sabemos que essa nova metodologia de trabalho exige muito mais do professor, tanto em relação ao conhecimento linguístico quanto ao tempo na organização das atividades, bem como na concretização das mesmas em sala de aula. Esta nova metodologia de ensino implica uma boa formação linguística do professor e a construção do saber por parte dos alunos. Não temos dúvidas de que o tempo gasto pelo professor terá resultado positivo mais à frente quando o aluno compreender os mecanismos gramaticais de base. Observe que ao longo de todo o percurso escolar dos alunos o professor gasta muito tempo repetindo regras e definições. Podemos nos perguntar que resultados práticos, efetivos isso tem. Será que os alunos quando chegam ao ensino superior demonstram ter apreendido os conteúdos gramaticais que fazem parte dos programas do ensino obrigatório do português? Basso e Pires de Oliveira (2012, p. 21) afirmam que

O fracasso das aulas de português no ensino médio e fundamental aparece também na nossa prática no ensino superior: os alunos têm dificuldade de redigir textos acadêmicos - e não se trata de adesão à norma culta, algo fácil de sanar, mas de pouca familiaridade com a construção de argumentos, com o levantamento de hipóteses e conclusões. $\mathrm{O}$ que vemos é que os alunos chegam à universidade com um domínio de escrita e leitura abaixo do esperado [...] Nas aulas de introdução aos estudos gramaticais em que discutimos a questão da Gramática Normativa é fácil perceber que os alunos sabem de cor a nomenclatura e alguns dos conceitos. [...] Eles sabem rótulos desprovidos de conteúdo. [...] A maioria devolve definições decoradas de sujeito e predicado sem saber identificá-los e, o que é pior, sem entender o que esses conceitos têm a ver com a língua que ele fala. 
Também sabemos que as condições atuais de trabalho dos professores não são favoráveis à implementação de novas metodologias. No entanto, essa nova postura pode render bons frutos, uma vez ultrapassadas certas barreiras. Xavier (2009) relata as vantagens da abordagem pela descoberta. Segundo a autora, no início os professores mostram uma certa desconfiança, mas à medida que vão se apropriando da nova metodologia de trabalho, "os balanços são positivos, não só por parte dos docentes, como também dos alunos, que adquirem os conhecimentos de modo mais reflexivo e consolidado" (XAVIER, 2009, p. 475). Vejamos o relato de uma professora do ensino fundamental de Portugal quando se refere ao resultado da nova metodologia aplicada a conteúdos de conhecimento explícito da língua.

Constatei que, depois de ter usado a abordagem tradicional para trabalhar, os alunos tinham construído conceitos errados: confundindo família de palavras com área vocabular. Uma vez usada a abordagem pela descoberta, a professora conclui que esta abordagem resulta para os alunos porque se divertem a descobrir e descobrem que aprender é divertido, porque são eles que «dirigem» o processo de aprendizagem como se um navio de Peter Pan se tratasse. Por mais dificuldades que apareçam, eles não desanimam e entretanto desenvolvem a sua autonomia e o seu pensamento científico. (XAVIER, 2009, p. 476)

Levando em consideração o exposto, verificamos que a atividade de construir gramáticas com os alunos muda a nossa atitude frente à língua. A sala de aula abre espaço à reflexão, ao treinamento do raciocínio científico, à medida que os alunos passam a observar o fenômeno linguístico em estudo, descrever os dados envolvidos, formular hipóteses, testar as hipóteses (validar ou refutar), elaborar regras sobre a sua língua. Cabe ressaltar que esse tipo de abordagem, que constrói o objeto ao invés de entregá-lo pronto, vai de encontro ao paradigma da gramática tradicional que ainda insiste em propagar a não evolução da língua.

Quando propomos ao professor de gramática uma metodologia que valorize o aluno enquanto participante ativo do processo de ensino-aprendizagem não estamos defendendo que não se deva ensinar a língua escrita, a norma culta falada pelos falantes com um grau alto de instruções. A questão, como já discutido neste trabalho, é que isso pode ser feito partindo de uma boa base linguística, via um tratamento científico da língua, o qual valoriza o português brasileiro, a língua dos alunos. Esse deve ser o principal papel da linguística nas escolas. 
Para encerrar, deixamos um pequeno trecho de Possenti (2016, s/p) que serve como um alerta aos agentes preocupados com os problemas de leitura, escrita e aprendizagem do português em nosso país:

Quando há um problema com as plantas, chamam-se botânicos e engenheiros florestais. Quando há um problema "de zica", chamam-se os médicos e os geneticistas. Mas quando há um problema com a escrita, não se chamam os linguistas: chamam-se jornalistas e donos de cursinhos.

Não é difícil constatar que alguma coisa neste processo está errada!

\section{Referências}

AVELAR, J. Inversão locativa e sintaxe de concordância no português brasileiro. Matraga, v. 16, n. 24, p. 232-252, 2009.

; CYRINO, S. Locativos preposicionados em posição de sujeito: uma possível contribuição das línguas Bantu à sintaxe do português brasileiro. Revista de Estudos Linguísticos da Universidade do Porto, v. 3, p. 55-75, 2008.

; GALVES, C. Tópico e concordância em português brasileiro e português europeu. In: COSTA, A.; FALÉ, Isabel; Barbosa, P. (Ed.). Textos Seleccionados do XXVI Encontro Nacional da Associação Portuguesa de Linguística. Lisboa: APL, 2011, p. 49-65.

. Concordância locativa no português brasileiro: questões para a hipótese do contato. In: MOURA, M. D.; SIBALDO, M. (Ed.). Para a História do Português Brasileiro. Maceió: Edufal, 2013. p. 103-132.

BASSO, R.; PIRES DE OLIVEIRA, R. Feynman, a Linguística e a curiosidade, revisitado. Matraga, Rio de Janeiro, v. 19, n. 30, p. 13-40, 2012.

CARDINALETTI, A. Gli instrumenti indispensabili della linguistica formale: Le nozioni di costituente, gerarchia, movimento. In: PIZZOLO TORQUATO, C.; ROMANELLI, S. (Org.). Estudos italianistas: ensino e aprendizagem da língua italiana no Brasil. Chapecó: Argos, 2014. p. 141-172.

CARTA EDUCAÇÃO, disponível em: http://www.cartaeducacao.com.br/reportagens/ brasil-mantem-ultimas-colocacoes-no-pisa/. Acesso em: 11 junho 2017.

CASTILHO, A. T. Prefácio. In: PIRES DE OLIVEIRA, R.; QUAREZEMIN, S. Gramáticas na escola. Petrópolis: Vozes, 2016, p.6-8. . Nova gramática do português brasileiro. São Paulo: Contexto, 2010.

CEGALLA, D. P. Novíssima gramática da língua portuguesa. 39. ed.. São Paulo: Editora Nacional, 1996.

COSTA, J. PB e PE: orientação para o discurso importa?. Estudos da Língua(gem) Estados diacrônicos e sincrônicos da Língua Portuguesa. v. 8, n. 1, p. 123-43, 2010. 
.; SANTOS, Ana Lúcia. A falar como os bebés: o desenvolvimento linguístico das crianças. Lisboa: Caminho, 2003.

COSTA, J. et al. Guião de Implementação dos Programas de Português do Ensino Básico: Conhecimento Explícito da Língua. Lisboa: Ministério da Educação/Direção-Geral de Inovação e de Desenvolvimento Curricular, 2011.

DUARTE, I. Conhecimento da Língua: Desenvolver a Consciência Linguística. Lisboa: Ministério da Educação/Direção-Geral de Inovação e de Desenvolvimento Curricular, 2008.

ILARI, R.; BASSO, R. O português da gente: a língua que estudamos, a língua que falamos. São Paulo: Contexto, 2006.

MIOTO, C.; FIGUEIREDO SILVA, M. C.; LOPES, R. E. V. L. Novo Manual de Sintaxe. São Paulo: Contexto, 2013.

NEGRÃO, E.; VIOTTI, E. Estratégias de impessoalização no português brasileiro. In: FIORIN, J. L.; PETTER, M. (Org.). África no Brasil: a formação da língua portuguesa. São Paulo: Contexto, 2008. p. 179-203.

. Contato entre quimbundo e português clássico: impactos na gramática de impessoalização do português brasileiro e angolano. Linguística, v. 30, n. 2, p. 289-330, 2014.

NOLL, V. O português brasileiro: formação e contrastes. São Paulo: Globo, 2008.

OTHERO, G. A. Sintaxe. In: SCHWINDT, L. C. (Org.) Manual de Linguística: Fonologia, Morfologia e Sintaxe. Petrópolis: Vozes, 2014.

PERINI, M. A. Gramática descritiva do português. São Paulo: Ática, 1995.

. Princípios de Linguística descritiva: introdução ao pensamento gramatical. São Paulo: Parábola Editoral, 2006.

. Gramática do português brasileiro. São Paulo: Parábola, 2010.

. Gramática descritiva do português brasileiro. Petrópolis: Vozes, 2016.

PIRES DE OLIVEIRA, R.; MEZARI, M. P. (Org.). Nominais Nus: um olhar através das línguas. Campinas: Mercado de Letras, 2012.

. Linguística, um laboratório a céu aberto. Reflexões sobre o ensino. In: GUESSER, S. (Org.). Linguística: pesquisa e ensino. Boa Vista: Editora da UFRR, 2016. p. $155-172$.

.; BASSO, R.; QUAREZEMIN, S. Construindo Gramáticas na Escola. Florianópolis: UFSC/CCE/DLLE, 2013.

.; QUAREZEMIN, S. Gramáticas na escola. Petrópolis: Vozes, 2016.

POSSENTI, Sírio. Linguistas na escola. Ciência Hoje, Coluna Palavreado, 2016. Disponível em: http://www.cienciahoje.org.br/noticia/v/ler/id/3088/n/linguistas_na_escola. Acesso em: 11 junho 2017. 
PONTES, E. O tópico no português brasileiro. Campinas: Pontes Editores, 1987.

QUAREZEMIN, S. Notas sobre adjunção - em defesa da iniciação científica nas escolas. In: GUESSER, Simone (Org.). Linguística: pesquisa e ensino. Boa Vista: Editora da UFRR, 2016a. p. 197-214.

. Construção de gramáticas: uma rota alternativa para o ensino de português nas escolas. In: QUAREZEMIN, Sandra (Org.). PETRIM - escritos do PET Letras UFSC. Florianópolis: PET Letras UFSC, 2016b. p. 15-20.

A sintaxe do sujeito: contribuições da linguística para o ensino do português brasileiro como segunda língua. Comunicação apresentada no II Congresso Ensino de português brasileiro na universidade italiana. Junho de 2017, Roma/Itália.

. CARDINALETTI, Ana. Non-topicalized preverbal subjects in Brazilian Portuguese, compared to Italian. Rivista Annali di Ca' Foscari. Serie occidentale, p. 383409, 2017.

RAPOSO, E. Teoria da Gramática: A Faculdade da Linguagem. Lisboa: Editorial Caminho, 1992.

XAVIER, L. G. (2009). Ensino da gramática: reflexões em torno do verbo. EXEDRA Revista Científica da Escola Superior de Educação de Coimbra, 1, p. 167-176, 2009.

. Ensinar Gramática pela Abordagem Ativa de Descoberta. EXEDRA Revista Científica da Escola Superior de Educação de Coimbra, volume temático Português: Investigação e Ensino, p. 467-478, 2012.

Data de submissão: 23/06/2017

Data de aceite: $21 / 08 / 2017$ 